\title{
Study the Challenge and Practices of Cooperative Training in Awi Zone Injebara Poly Technic Collage
}

\author{
Solomon Tilahun Dilie \\ Ethiopian Institute of Textile and Fashion Technology, Bahir Dar University, Bahir Dar, Ethiopia \\ Email address: \\ Solomon.tilahun67@gmail.com
}

To cite this article:

Solomon Tilahun Dilie. Study the Challenge and Practices of Cooperative Training in Awi Zone Injebara Poly Technic Collage. International Journal of Vocational Education and Training Research. Vol. 7, No. 1, 2021, pp. 14-20. doi: 10.11648/j.ijvetr.20210701.13

Received: September 16, 2020; Accepted: December 7, 2020; Published: May 8, 2021

\begin{abstract}
The main objective of this study was to assess the challenges and practices of cooperative training in Injibara poly Technique College. The research methodology employed in this study was descriptive survey method. Simple random sampling was used to select sample departments and respondents. The data are analyzed and interpreted quantitatively as well as qualitatively, Data from management of enterprise and college through interview. Percentage was employed as statistical tools to analyze data. The findings of this study revealed that the trainers are not qualified and experienced; stakeholders have no adequate awareness on the purposes, objectives, and the implementation process of cooperative training. Questionnaire, interview and document analysis were data collection tools employed in this study. Percentage was employed as statistical tools to analyse data. The findings of this study show that the college trainers are not well qualified and experienced; enterprises have no adequate awareness on the purposes, objectives, and the implementing process of cooperative training. The involvement of companies in Planning, Implementing and evaluating enterprise was low; enrollment of trainees was not implemented as indicated in the national TVET strategy, and shortage of enterprise offering companies were high. Un similarity of activities during enterprise with the activities in the world of work was major factors that affect the implementation of the program, lack of collaboration between stakeholders, lack of capable supervisor, lack of appropriate machines and training materials, shortage of budget, lack of promotion activities, lack of training for trainers, and lack of subject matter and pedagogical knowledge of trainers moderately affected implementation of enterprise program, and lack of transportation service during enterprise. based on the findings and conclusions, the following points were recommended to address the existing challenges in the zone under study; staff development in the college; organized TVET systems in companies and TVET colleges; raise-social awareness about the importance of enterprise in the zone for all stakeholders should seriously be considered; and the TVET colleges strives to implement trainees enrollment as indicated in national TVET strategy. Necessary facilities should also be fulfilled.
\end{abstract}

Keywords: Cooperative Training, Enterprise, Poly Technique College, Challenges and Opportunity

\section{Introduction}

Technical and Vocational Education and Training (TVET) is concerned with the acquisition of knowledge and skills for the world of work. TVET is defined by UNESCO (United Nations Educational, Scientific and Cultural Organization) as those aspects of the educational process involving, in addition to general education, the study of technologies and related sciences and the acquisition of practical skills, attitudes, understanding and knowledge relating to occupation in various sectors of economic life. [1]

The Ethiopian TVET system will be outcome-based with competencies certified by an independent testing body, which is centre of competency (COC). This body evaluates the trainee's without consideration of the actual learning and training process which is conducted in the TVET institutions. By using COC evaluation method one can easily compare cooperating training comes with the traditional formal training process. In outcome-based TVET system all training providers, TVET institutions entered into competitions by testing trainees and certifying their ability to meet the Ethiopian occupational standards (EOS) which is set by employers. This standard is strengthened using co-operative training. 
The new TVET strategy defines the framework for the implementation of cooperative and the integration of enterprise based training: since the reformed TVET system is outcome based, it allows for great flexibility in the actual training delivery process. Public and private TVET providers are free to choose how best to organize TVET for their target groups according to the requirement of the labour market in their state. However, they can choose to adopt and adapt model curricula which are developed for each occupational standard, recommending training content, its organization and its duration.

The word "cooperative" refers to the two parties providing training: the concept "system" means that the two parties do not operate independently of one another, but rather coordinate their efforts. The guiding principle is that as all parties involved, namely: the industry, the trainees and TVET institutions will gain immediate and long-lasting benefit; they will choose it.

The term "cooperative training" encompasses all forms of training conducted jointly by TVET institutions and enterprise. The training takes place alternatively in the school environment and in the real-life environment of the workplace.

Most of the training occurs in the enterprise where practical skills and application of theory take place. The trainee goes to TVET institutions for only limited period of time $(30 \%)$ to acquire theoretical knowledge and $70 \%$ for basic skills in the specific unit of competence. Enterprise and TVET institutions are expected to cooperate in planning, implementing and assessing cooperative training. In the planning phase enterprise are asked to state their expectations for training outcomes: what skills, knowledge and attitudes do they wish trainees to acquire at the end of their training. Enterprises are further expected to contribute their expertise to how the desired training outcomes will be achieved. In the implementation phase enterprises participate in implementation by providing practical training on their premises. They communicate with TVET institution and other enterprise regarding the achievement of training objectives; further training needs, problems, experience during training and other issues. In the assessment phase enterprises take part in the communicate that perform the final assessment of training out comes, e.g. through occupational assessment. From this end there are different factors needed to be fulfilled such as partner establishing a TVET institutions training curriculum, a training coordinator, etc.

Injibara Polytechnic College aims to deliver formal, informal and non-formal education and training to those who need to acquire a required knowledge and skill according to the need assessment study of the industry. Besides this, this college is giving industry extension service for micro and small enterprises especially for those manufacturing enterprises through technology transfer capability, according to Federal TVET policies the college should be implemented cooperative training policies means of $70 \%$ is practical work and $30 \%$ is theoretical knowledge that support the real world work, But, in Injibara polytechnic college cooperative training is not implementing due to so many cases. Such as, the program implemented in the college, but organizations are not willing to discharge their responsibilities regarding cooperative training, Lack awareness about the planning of program, assessment the result, the poor management system and Communication gap between the college and enterprise and do not assigned trainees in relation to their field of studies. Due to the above root cases: the students do not able to perform the task, Are not effective in workplace, not job creative and need retraining.

\subsection{Theory of Technical and Vocational Education and Training}

The present vocational education system called TVET system defined as combination of theory, practice, elements of education such as specific calculation of knowledge about certain materials, working methods and so on combined with practical training through instruction in the work shop of a training institution or practical work in an enterprise. TVE is concerned and skills for the world of work. In the past various terms have been used to describe elements of the field that are now conceived as comprising TVET. According to [11]. The definition of TVET: refers to all forms \& levels of education process involving, in addition to general knowledge the study of technology \& related sciences \& the acquisition of practical skills, know how, attitudes \& understanding relating to occupations in the various sectors of economic \& social life in educational institutions or through Co-operative programs organized jointly by educational institutions, on the one hand and industrial, agricultural, commercial or any other Undertaking related to the world of work, on the other. This is any education, training \& learning activity leading to the acquisition of Knowledge, understanding \& skills which are relevant for employment or self-employment. TVET serves here as an overarching term to describe all kinds of formal, non-formal and informal training \& learning provided by or in all different institutions, providers \& learning locations.

\subsection{Philosophies of Technical and Vocational Education and Training}

TVET in Ethiopia has various conceptual \& non Conceptual philosophies. One of the conceptual philosophies is "stakeholders involvement", specifically stakeholders are needed to play a major role in various function as the TVET system, one of these function is stakeholders are needed since they contribute much to the success of the system by participating in "TVET delivery through the provision of training to their own staff, offering internship to trainees \& providing apprenticeship training." Concerning TVET delivery, the non-public sector needs to play a decisive role. It already contributes significantly through in-company TVET schemes \& in particular, through wide spread traditional apprenticeship training provided in the micro \& small business sector. In addition to these employers based TVET schemes, non-government TVET institutions will 
become an increasing important pillar of the overall TVET supply. Hence, in short among various role of improving \& widening training delivery made in the central role that stakeholder could play; this led us to the discussion cooperative training which warrants a genuine Cooperation between TVET institution and stakeholders. [5]

\subsection{Technical and Vocational Education and Training in Ethiopia}

Ethiopia has been having an alphabet of its own for many centuries and it has been running its educational system in religious institutions.

Ethiopian Education System [4] However, since 2000/01 a massive expansion of this sub-sector has been operational. The strategic thinking behind the expansion of the TVET sub-sector is to meet the middle level human power demand of the industry, service sector, and commercial agriculture, which have become very essential to the overall development of the country.

TVET is an instrument for producing technicians equipped with practical knowledge, who unlike in the past, would be job creators rather than expecting jobs to be provided by the government. The objective is to provide quality education and training in the TVET sub-sector. To this end, the curriculum was revised; skill-upgrading training was given to TVET teachers, and experienced teachers were employed to overcome the shortage of teachers. In collaboration with the private sector and government enterprises, an apprenticeship program was also introduced to develop the skill of the trainees before their deployment to the world of work [16].

\subsection{Resume of Cooperative Training in Ethiopia}

Cooperative training system in Ethiopia is derived from the "dual training system" of Germany and refers to mode of training delivery of technical and vocational education and training that combines training in enterprise and institution based on a training plan collaboratively designed and implemented by industries and respective TVET institutions. Under this system, the industries/companies and the TVET institutions share the responsibility of providing the trainee with the best possible job qualifications, the former essentially through practical training and the latter by securing an adequate level of specific, general and occupation-related basic competency. The word "cooperative" refers to the two parties providing training: the concept "system" means that the two parties do not operate independently of one another, but rather coordinate their efforts. The guiding principle is that as all parties involved, namely: the industry, the trainees and TVET institutions will gain immediate and long-lasting benefit; they will choose it [15].

This cooperative training, as stated above, is a new phenomenon in the Ethiopian TVET System. In cooperative training, the trainees are expected to spend a certain part of their time in the training institute and most of the time in an enterprise that undertakes tasks related to their occupational training. It is believed that this type of cooperation benefits both the training institution and the enterprise leaving aside the advantages the government and the trainees derive from it.

Cooperative training is expected to play its role in improving the quality of the current Ethiopian TVET system. Any enterprise who can provide a working place to trainees, machines for training, tools, consumables, materials and which can also assign a training coordinator/ supervisor can be a cooperative training partner. As far as occupational activities of the enterprises, in one way or another, if the activities of an enterprise have similarity with occupational training, any enterprise, large or small, can take part in cooperative training.

In order to keep current with the state of the art practice, there is a need for collaboration between TVET institutions and enterprises to enable students gain skills and to enable teachers to retool in their own occupations. In this relationship, tangible benefits accrue to both educational institution and the informal/formal sector [6]. Here, it has been tried to explain what cooperative training is, the participants in the program, and the benefit derived from the program by each participant. The source and the way cooperative training is expected to be put into practice and the condition of cooperative training, including the major problems being faced, in Ethiopia have been discussed.

The literature review part of the research has tried to further emphasize the objectives of TVET, mention some of the major institutional factors (both human resource related and none human resource related) that influence the training of TVET students. The human resource related factors included TVET management, interpersonal relationships, training staff, and guidance and counselling services. The none human resource related factors, on the other hand, comprised of such things as curriculum content, school facilities, instructional materials related factors, on the other hand, comprised of such things as curriculum content, school facilities, instructional materials, and cooperative training. The recent development in TVET in Africa, particularly Ethiopia has been to some extent raised here and there throughout the chapter.

\subsection{Phases in Cooperative Training}

\subsubsection{Planning Cooperative Training}

According to TVET strategy [7] states that, before starting cooperative training program, enterprises and TVET institutions should negotiate and agree on types of occupations in demand and jointly develop a training plan right from the occupational standard or from a curriculum derived from this. A training plan shows topics of the curriculum to be taught either enterprise or in TVET institutions. Cooperative training cannot be successful without a training plan similarly [7]. indicates that Planning of a cooperative training can also begin at the outset of curriculum development. The curriculum developers/trainers at a TVET institution should invite relevant experts from companies to take part in the process in order to jointly plan topics/competences to train at TVET institution or at the company/work place. Accordingly, this training plan forms an integral part of the curriculum, maintained both at the 
training institutions and at the companies.

\subsubsection{Establishing Cooperative Training Sites}

Cooperative training needs two venues: one at TVET institution and one at enterprise. These two venues must be secured and assigned for the program by both parties. Remember: cooperative training cannot be done at one site only [7].

\subsubsection{Signing of Training Agreement}

Memorandum of Understanding is a major reference document showing every roles and responsibilities of partners in cooperative training. Therefore, this document has to be signed by representatives of top managements of enterprise and TVET College respectively and kept at both places for regular reference [7].

\subsubsection{Monitoring Training Progress and Evaluation}

Monitoring trainees and enterprise records will be necessary to determine training progress. This should be a balance between periodic formal performance reviews by the vocational counsellor/TVET-trainer and informal daily observation and feedback by the enterprise trainer. Assessment of trainers during the training program is held in enterprise and TVET institution by the enterprise and TVETtrainers. It is believed that majority of trainees undergone cooperative training shall pass the assessment because they experienced the real competencies required in the occupational standard. Competency includes what are known as employability skills the ability to support the work place through communication, team work, problem solving, selfmanagement, planning, organizing, technologies, learning, and taking initiative. [8]

\subsubsection{Major Challenges of Cooperative Training in TVET}

With the intention of producing technical and professional skilled man power, TVET in Ethiopia has been practiced since 1940s. However, the expectation and the actual practice do not seem to meet each other. Initial training is still input oriented and follows curricular requirements instead of workplace and labour market requirements. Extending its suggestions tried to put what should be done in the coming five years. TVET program will focus on creating quality oriented and demand driven system that can produce adequate and skilled technical and vocational human resource for the implementation of Agriculture development led industrialization and poverty reduction strategy [10].

\section{Methodology}

These sections of the research paper should be concise. The audience reading the paper will always want to know what materials or methods that were used. The methods and materials may be under subheadings in the section or incorporated together. The main objective for these sections is to provide specialized materials, general procedures, and methods to judge the scientific value of the paper.

\subsection{Method of the Study}

In this study, a descriptive survey research method is employed. This research method is chose because, it enables to study the current situation that exist, opinions that are held and processes that are going on widely. It has the potential to provide a lot of information obtained from a large sample of individual. It is also said to be adaptable to obtain personal opinions and attitudes using questionnaires.

Both quantitative and qualitative research data analysis methods were employed. The quantitative method was applied to evaluate and obtain relevant data through questionnaire to the target respondents focusing on challenges and practices of cooperative training from the college. The qualitative method was used getting further information so as to strengthen and the data obtained through quantitative method.

\subsection{Populations of Injibara Poly Technique Collage \& Stockholders}

The total populations of our study (trainers, trainees \&enterprise) are listed below. 580 Trainees, 10 trainer, 3 department head \& 10 enterprise total 703 were the population of the research to been conducted.

\subsection{Sampling Technique and Procedure}

The study focuses on the department of constructions, IT and manufacturing using simple random sampling technique and ten enterprises that participating in cooperative training is selected randomly. The sample size taken based on the quantity of the target population in the poly technique \&enterprises (see table 1). The Trainer \& Trainees are selected using simple random sampling technique. Enterprises owners are selected for interview. Systematic sample is done by picking every 5 th unit at the regular interval. [13].

Table 1. Population and sample size.

\begin{tabular}{|c|c|c|c|c|c|c|c|c|c|c|c|}
\hline \multirow{2}{*}{ No } & \multirow[t]{2}{*}{ Department } & \multicolumn{2}{|c|}{ Department Head } & \multicolumn{2}{|c|}{ Trainers } & \multicolumn{2}{|c|}{ Trainees } & \multicolumn{2}{|c|}{ Enterprises } & \multicolumn{2}{|l|}{ Total } \\
\hline & & Total & Sample & Total & Sample & Total & Sample & Total & Sample & Total & Sample \\
\hline 1 & Manufacturing & 1 & $1(100 \%)$ & 45 & $10(22.22 \%)$ & 230 & $46(20 \%)$ & 5 & $2(40 \%)$ & 281 & $59(45.55 \%)$ \\
\hline 2 & Construction & 1 & $1(100 \%)$ & 30 & $6(20 \%)$ & 200 & $40(20 \%)$ & 3 & $1(33.33 \%)$ & 234 & $48(43.33 \%)$ \\
\hline 3 & Information Technology & 1 & $1(100 \%)$ & 35 & $7(20 \%)$ & 150 & $30(20 \%)$ & 2 & $1(50 \%)$ & 188 & $39(47.5 \%)$ \\
\hline Total & & 3 & $3(100 \%)$ & 110 & $23(20.74 \%)$ & 580 & $116(20 \%)$ & 10 & $4(41.11 \%)$ & 703 & $146(45.46 \%)$ \\
\hline
\end{tabular}

\section{Results and Discussion}

This chapter deals with the results and discussion data related to the background information of the sample population and 
their responses to the activities that are see in the instruments.

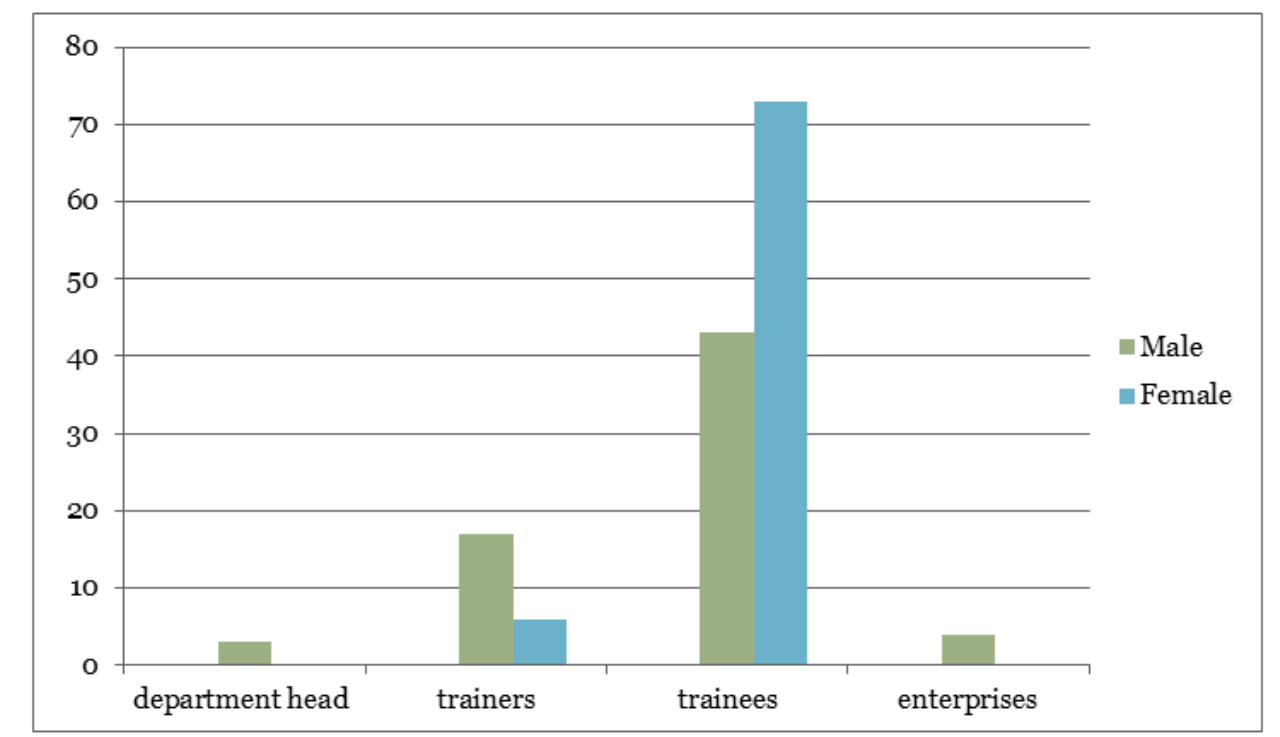

\begin{tabular}{|l|r|r|r|}
\hline & Male & Female & \\
department head & 3 & & total \\
\hline trainers & 17 & 0 & 3 \\
\hline trainees & 43 & 6 & 23 \\
\hline enterprises & 4 & 73 & 116 \\
\hline
\end{tabular}

Figure 1. Characteristics of the Respondents Sex.

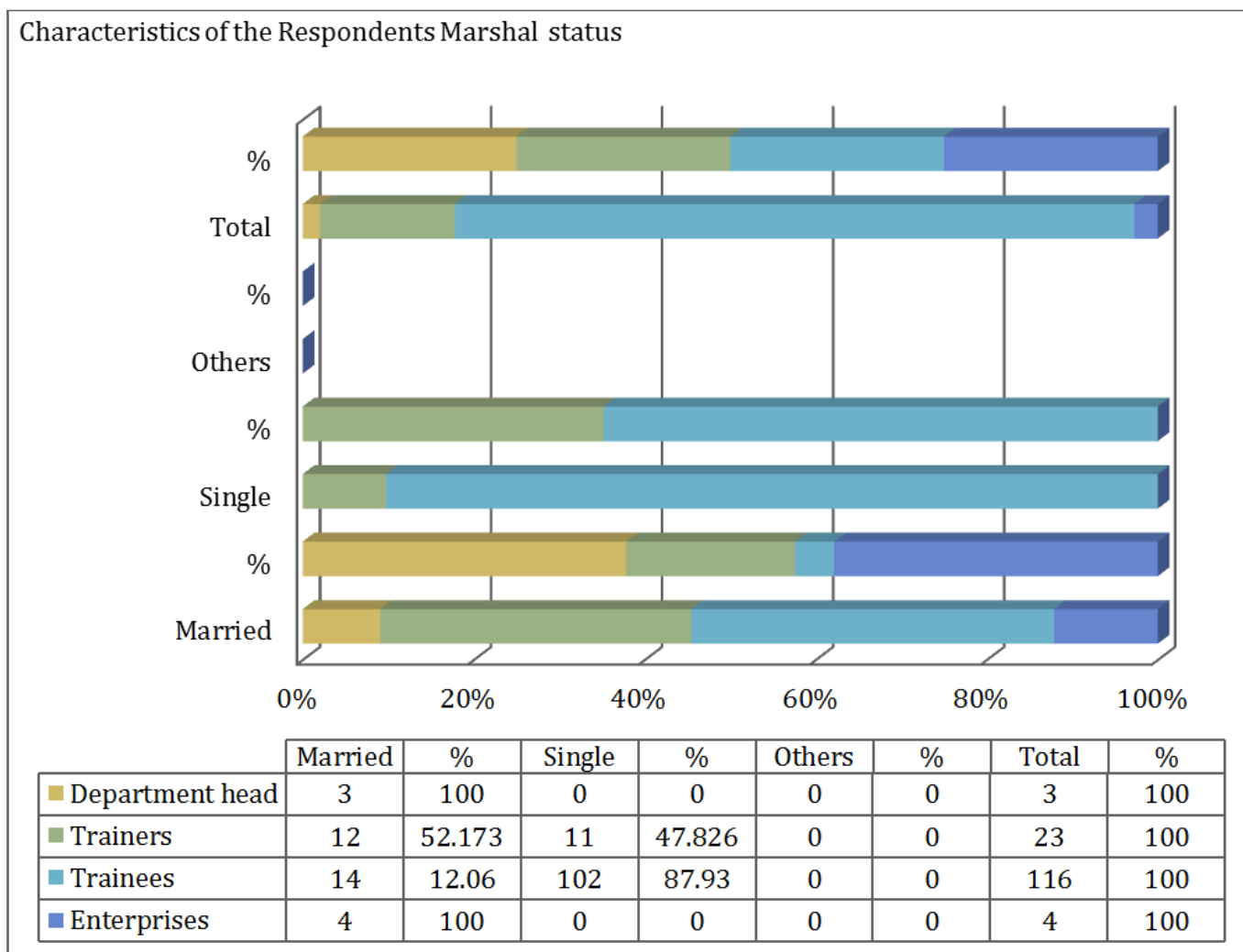

Figure 2. Characteristics of the Respondents Marshal status. 


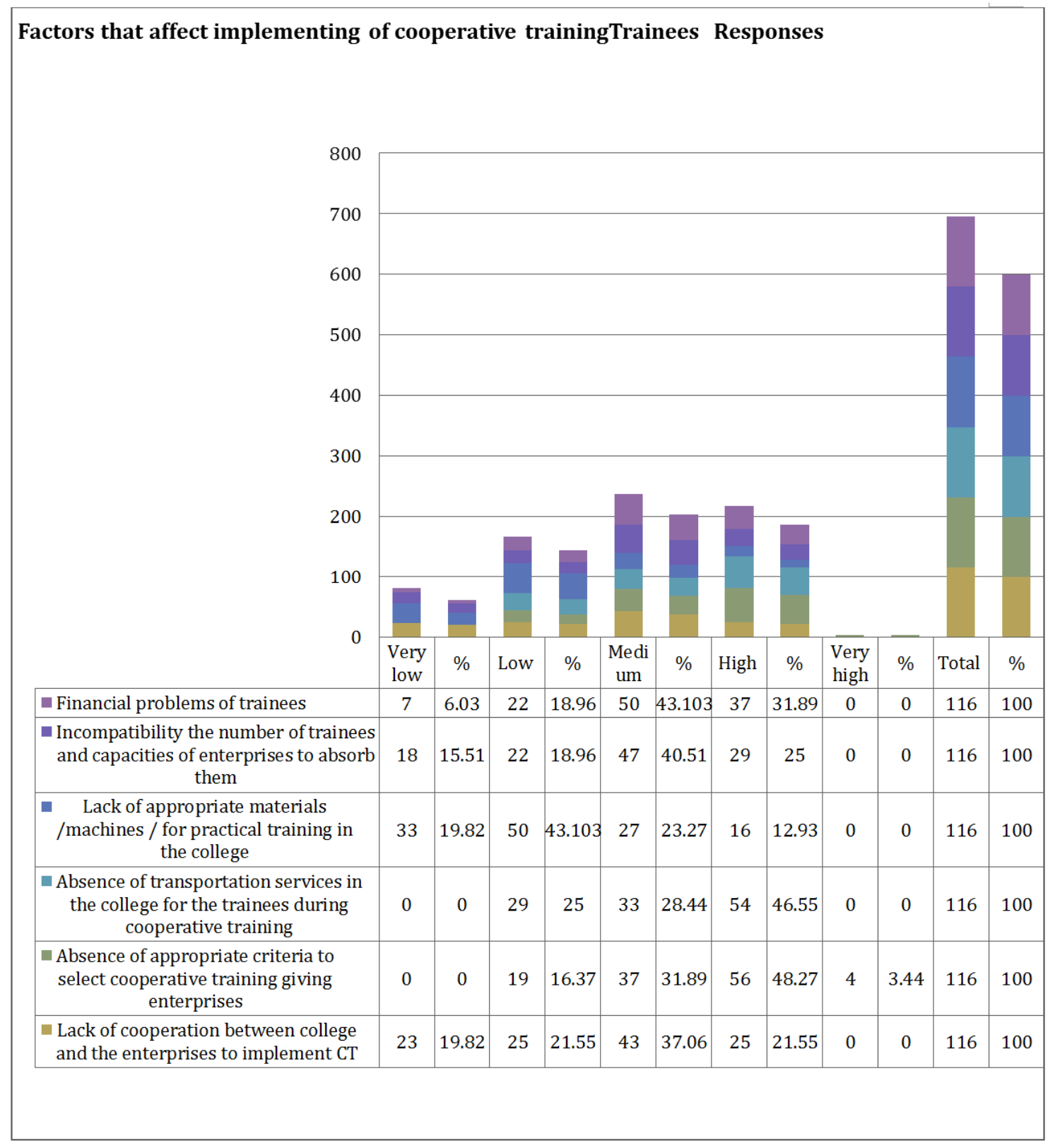

Figure 3. Factors that affect implementing of cooperative training Trainees Response.

As we can see from item 1 of graph $4.1,73(62.9 \%)$ of trainee respondents were females. So, it indicates that there was good participation of female trainee in the college. Concerning enterprise respondents $0(0 \%)$ were females and $4(100 \%)$ of the respondents were males. So, this implies that there is very low participation of females as enterprise as compared to their male counterpart. Therefore, it requires encouragement and motivation of females to bring them to such activities in the selected enterprises.

In general, the result of the data tells that participation of enterprise in planning CT was low, participation by setting criteria to select companies for CT was also low and Participation in setting rules and regulations regarding CT was low. Supporting this result, some of the interviews said that "our enterprises are one of cooperative training giving enterprises; we do not know about how our enterprises prepared the CT plan and evaluate the progress of the program.

\section{Conclusion}

From the results, it can be concluded that the accessibility of experienced and skilled trainers is vital element for the supplies of quality training. Opposing to its importance, the study show that college under study area less qualified trainers with practical skill. To increase the quality of training and implementing of TVET strategy, the current practices of the College should be providing training in teamwork with enterprises and giving training from level 5 to level 1 with the ratio of 2:8:13 which indicated in the strategy. But, in the college under study area all training programs more of the trainees are enrolled in level II, level III and level IV. 
Consequently, with respect to the national TVET strategy, the current practices of the college appear to be unreliable. Despite the fact that cooperative training plans were prepared, the participation of enterprises in the planning, implementing and evaluation process of cooperative training was not adequate, this show that enterprises had no significance contribution in the planning, implementing and evaluation of the plans and there was lack of strong teamwork among enterprises in planning for cooperative training. Most of the factors that affect implementation of cooperative training were averagely affected the success of cooperative training in the college. These factors are Cooperation between college and enterprises, relevance of training materials /machines / in the College, incompatibility between the number of trainees and capacities of enterprises and financial problem of trainees; the rests were highly affected the success of cooperative training in the college. Regarding to the capability, accessibility and readiness of enterprises, there was inaccessibility of manufacturing and service enterprises, materials / machines /in the cooperative training giving enterprises, capacity of enterprises and readiness of enterprises to implementing cooperative training were not suitable.

\section{References}

[1] Ayalew. ((2000)). "Educational Policy and Management of Change".(Unpublished Course Guide). Addis Ababa: A. A. U.

[2] Christenseen, j. (2008). the interview is conduct on a face to face basis.

[3] Developement. (2014). technical (Ayalew, (2000)) \&vocational education training. p. 56.
[4] Developmen, J. o. (2017). Challenges and Prospects of Technical and Vocational Education. p. 6.

[5] Developmen, S. (No. 5, 2019). Challenges and Prospects of Technical and Vocational Education. p. 17.

[6] Development, J. o. (No. 5, 2019). Challenges and Prospects of Technical and Vocational Education. Dawit Fantaye, 1.

[7] Education, T. E. (2017). The Cooperative Training Delusion in Ethiopia College-Industry Partnership Discrepancy in the TVET System of the Regional State of Amhara. melaku mengistu, 1 .

[8] FDRE. (2005). proclamation to proviode to the organaization of atechnical \&vocational education \& training system federal negarit gazeta of thefder proc..

[9] From Wikipedia, t. f. (2017). Agew Awi Zone. p. 1.

[10] G/Michael, D. E. (2014, May). monitoring training progeress \&evaluation. p. 18.

[11] G/Michael, D. E. (2014, May). PRACTICES AND CHALLENGES OF. p. 18.

[12] Girma. z. (2009). "fudamental of adminsteration in vocational education ". p. 12.

[13] Masuku, M. B. (Nov 2014, September 16). Sampling techniques \& determination of sample. International Journal of Economics, Commerce and Management.

[14] Mekuria. (2006). cooperative treianing. addis abeba: 1.

[15] MOE. (2007). building etiopian coperative training frame work. 1997 training of techer/trainers in tecnical \&vocational education. Paris UNESCO/UNEVOC.

[16] MOE. (2008). national tecnical \&vocational education \& trinig strategy 2 nd education.

[17] MOE. (2010). co-coperative \& in company training hand book, list edition moe. 